\title{
Hubungan antara depresi, gangguan fungsi kognitif, dan kualitas hidup penduduk usia lanjut di Desa Pedawa, Kabupaten Singaraja, Bali
}

\author{
Pande Made Juniarta ${ }^{1}$, IGP Suka Aryana ${ }^{2}$
}

${ }^{1}$ Program Studi Pendidikan Dokter Spesialis Penyakit Dalam, Fakultas Kedokteran Universitas Udayana/RSUP Sanglah, Denpasar, Bali, Indonesia ${ }^{2}$ Departemen/KSM Penyakit Dalam, Fakultas Kedokteran Universitas Udayana/ RSUP Sanglah, Denpasar, Bali Indonesia

pandejuniarta86@gmail.com
Tanggal diterima : 30 Arpil 2018

Tanggal Disetujui : 16 Mei 2018

Tanggal Diterbitkan : 5 Juni 2018
Latar Belakang: Depresi adalah gangguan psikiatri yang paling sering ditemukan pada usia lanjut di seluruh dunia. Insiden depresi pada usia lanjut sering tidak terdeteksi dan bentuk depresi onset lambat sangat terkait dengan gangguan kognitif, risiko penyakit, kecacatan, dan kualitas hidup yang rendah.

Tujuan: Penelitian ini bertujuan untuk mengetahui hubungan antara depresi, gangguan kognitif, dan kualitas hidup penduduk di Desa Pedawa, Singaraja.

Metode: Penelitian ini merupakan penelitian potong-lintang yang dilakukan pada 13-14 Agustus 2016 dengan sampel sebanyak 117 orang. Penilaian depresi menggunakan kuesioner GDS-15, gangguan kognitif menggunakan kuesioner AMT, dan kualitas hidup dinilai menggunakan kuesioner EQ5D. Sampel diperoleh dengan menggunakan metode konsekutif sampling dan data dianalisis menggunakan SPSS versi 16.0 .

Hasil: Karakteristik sampel adalah 54 orang $(46,2 \%)$ pria dan 63 orang $(53,8 \%)$ adalah wanita. Prevalensi depresi didapatkan sebanyak 24 orang (20,5\%) dan gangguan kognitif sebanyak 64 orang $(54,7 \%)$. Sampel dengan kualitas hidup yang baik, sedang dan buruk masing-masing adalah 35 (29,9\%), 66 (56,4\%), dan 16 orang (13,7\%). Hasil analisis bivariat didapatkan hubungan bermakna antara depresi dengan gangguan fungsi kognitif dan tingkat ekonomi ( $p<$ $0,05)$. Sedangkan hubungan antara depresi dan kualitas hidup diperoleh hasil yang tidak bermakna $(p=0,49)$.

Simpulan: Didapatkan hubungan yang bermakna antara depresi dan gangguan kognitif dan tingkat ekonomi pada penduduk di Desa Pedawa, Kecamatan Singaraja, Bali

Kata kunci: depresi, gangguan kognitif, kualitas hidup, usia lanjut

Background: Depression is the most psychiatric disorder found in the elderly around the world. The incidence of depression in old age is often undetectable and the form of late-life depression is strongly associated with cognitive impairment, risk of disease, disability, and low quality of life.

Objective: This study aims to determine the relationship between depression, cognitive impairment, and the quality of life of population in Pedawa, Singaraja.

Method: This study is a cross-sectional study conducted on August 13-14, 2016 with a sample of 117 people. Assessment of depression using GDS-15 questionnaire, cognitive impairment using AMT questionnaire, and quality of life was assessed using EQ5D questionnaire. The sample was obtained using consecutive sampling method and the data then analyzed using SPSS version 16.0 .

Results: Characteristics of the sample were 54 (46.2\%) men and 63 (53.8\%) were women. Prevalence of depression and cognitive impairment were 24 people (20.5\%) and 64 people (54.7\%) respectively. Sample with good, medium and bad quality of life were 35 (29.9\%), 66 (56.4\%), and 16 people (13.7\%) respectively. The results of bivariate analysis found a significant association between depression with impaired cognitive function and economic level $(p<0.05)$, while the association between depression and quality of life obtained results that were not significant $(p=0.49)$.

Conclusion: There are significant association between depression and cognitive impairment and economic level in Pedawa Village residents, Singaraja District, Bali.

Keywords: depression, cognitive impairment, quality of life, elderly

\section{PENDAHULUAN}

Depresi merupakan salah satu penyebab utama disabilitas pada usia lanjut yang ditandai oleh kesedihan yang mendalam, perasaan tidak berarti dan bersalah, menarik diri dari orang lain, tidak dapat tidur, kehilangan selera makan, hasrat seksual dan minat serta kesenangan dalam aktivitas yang biasa dilakukan. ${ }^{1}$ Kejadian depresi seringkali tidak 
terdeteksi pada usia lanjut oleh karena gejala depresi yang menyerupai proses penuaan. Prevalensi depresi pada populasi usia lanjut sangat bervariasi. Pada populasi yang menjalani rawat inap pada ruang perawatan akut, prevalensi depresi mencapai $76,3 \%$, sedangkan pada pelayanan kesehatan primer mencapai $5-17 \%$. Pada studi komunitas prevalensi depresi dikatakan mencapai 17,5-58,2\%.1,2,3 Depresi lebih banyak dialami oleh wanita dan faktor risiko depresi meliputi usia, kemampuan copying yang buruk, keterbatasan fisik, rendahnya status fungsional, dan gangguan fungsi kognitif. Gangguan fungsi kognitif berhubungan erat dengan kejadian depresi, dimana kejadian depresi apabila bersamaan dengan gangguan fungsi kognitif dapat berdampak terhadap status kesehatan fisik, status fungsional, dan tingkat mortalitas penduduk usia lanjut., ${ }^{1,2}$ Prevalensi gangguan fungsi kognitif pada usia lanjut diperkirakan mencapai $17-36 \%$ di Amerika Serikat dimana sebagian besar kasus berkembang menjadi demensia di kemudian hari. Pada studi lain didapatkan prevalensi gangguan fungsi kognitif yang bervariasi antara 9,6-26,1\% tergantung pada metode diagnostik dan tingkat pendidikan subjek pada masing-masing populasi. ${ }^{4,5,6}$

Beberapa studi menunjukkan bahwa kejadian depresi terkait dengan gangguan fungsi kognitif dan penurunan status fungsional. Sedangkan pada sisi lain, pemulihan fase remisi dari disfungsi kognitif dapat meningkatkan kerentanan individu untuk mengalami episode depresi pertama kali maupun rekurensi kejadian depresi di masa yang akan datang. Keluhan-keluhan kognitif seperti kesulitan dalam memutuskan sesuatu, dan kesulitan dalam berkonsentrasi juga termasuk dalam kriteria mayor depresi sesuai DSM-IV., Dalam beberapa studi terakhir mengacu pada keluhan kognitif pada depresi, secara konsisten didapatkan hasil adanya implikasi keluhan depresi terkait fungsi memori, gangguan perhatian, dan gangguan dalam memutuskan kecepatan dalam memproses sesuatu. ${ }^{8,9}$

Kualitas hidup menurut World Health Organization (WHO) didefinisikan sebagai persepsi individu terhadap posisi mereka dalam konteks sistem nilai dan budaya di tempat mereka hidup dalam hubungan dengan tujuan dan harapan hidup. Kualitas hidup merupakan sesuatu yang bersifat multidimensional dan biasanya terbagi dalam tiga kategori, yaitu: kualitas hidup global, kualitas hidup terkait kesehatan, dan kualitas hidup terkait penyakit spesifik. Kejadian depresi telah diketahui berasosiasi dengan rendahnya kualitas hidup, tingkat mortalitas, dan pencapaian hasil terapi yang tidak optimal. ${ }^{10}$

Studi ini bertujuan untuk mengetahui hubungan antara depresi dengan gangguan fungsi kognitif dan kualitas hidup pada penduduk lanjut usia di Desa Pedawa, Singaraja.

\section{METODE}

Studi ini merupakan studi analitik potong lintang yang dilakukan pada tanggal 13-14 Agustus 2016 dengan sampel berjumlah 117 orang dan dipilih secara konsekutif. Sampel penelitian adalah semua penduduk yang berusia lebih dari atau sama dengan 60 tahun yang tinggal atau berada di Desa Pedawa, Kecamatan Banjar, Kabupaten Buleleng yang memenuhi kriteria inklusi (usia $\geq 60$ tahun, bersedia menjadi sampel penelitian) dan kriteria eksklusi (sedang menderita infeksi akut, penyakit keganasan, imobilisasi atau ketergantungan berat, ketidakmampuan untuk diwawancara). Penilaian gangguan fungsi kognitif menggunakan kuisioner Abbreviated Mental Test (AMT) yang dikelompokkan menjadi terdapat gangguan fungsi kognitif (skor 0-7) dan tidak terdapat gangguan fungsi kognitif (skor 8-10); depresi menggunakan kuisioner Geriatric Depression Scale-15 (GDS15) yang dikelompokkan menjadi depresi (skor 5-15) dan tidak depresi (skor 1-4). Sedangkan kualitas hidup dinilai menggunakan kuisioner EQ5D. Data yang diperoleh dianalisis menggunakan SPSS versi 16.0. Data deskriptif menampilkan tentang karakteristik sampel (usia, jenis kelamin, tingkat pendidikan, pekerjaan dan tingkat ekonomi). Faktor-faktor yang terkait dengan depresi (usia, jenis kelamin, status pernikahan, tingkat ekonomi, tingkat pendidikan, kualitas hidup dan gangguan fungsi kognitif) dianalisis dengan uji bivariat berupa uji parametrik independent $T$-test dan uji non parametrik Chi-Square. Bila data tidak memenuhi syarat uji non parametrik maka selanjutnya dianalisis menggunakan uji Fisher atau uji Kolmogorov-Smirnov.

\section{HASIL}

Berdasarkan karakteristik sampel pada Tabel 1, didapatkan sebanyak 54 orang $(46,2 \%)$ adalah laki-laki dan 63 orang $(53,8 \%)$ adalah perempuan. Rentang usia paling banyak adalah antara $60-74$ tahun $(74,4 \%)$, sebagian besar $(56,4 \%)$ sampel tidak mengenyam pendidikan, dan sebagian besar sampel bekerja sebagai petani cengkeh $(69,2 \%)$. Pada karakteristik tingkat ekonomi sampel, sebagian besar $(63,2 \%)$ berada pada tingkat ekonomi rata-rata. Hasil skrinning depresi pada Tabel 2, didapatkan sampel dengan depresi sebanyak 24 orang $(20,5 \%)$ dan tanpa depresi sebanyak 93 orang $(79,5 \%)$. Gangguan fungsi kognitif didapatkan pada 64 orang $(54,7 \%)$ dan tanpa gangguan kognitif sebanyak 53 orang (45,3\%). Hasil analisis kualitas hidup sampel didapatkan sampel dengan kualitas hidup baik, sedang dan buruk berturut-turut sebanyak 35 orang $(29,9 \%)$. Hasil analisis bivariat didapatkan hubungan yang bermakna antara depresi dengan gangguan fungsi kognitif dan tingkat ekonomi ( $p<0,05$, Tabel 2). Sedangkan hubungan antara depresi dan kualitas hidup didapatkan hasil yang tidak bermakna $(\mathrm{p}=0,49$, Tabel 2$)$. 
Tabel 1. Karaktistik Sampel

\begin{tabular}{lc}
\hline Karakteristik & N (\%) \\
\hline Jenis Kelamin & \\
Laki-Laki & $54(46,2)$ \\
Perempuan & $63(53,8)$ \\
Usia (tahun) & \\
$60-74$ & $87(74,4)$ \\
$75-90$ & $28(23,9)$ \\
$>90$ & $2(1,7)$ \\
Tingkat Pendidikan & \\
Tidak Sekolah & $66(56,4)$ \\
SD & $44(37,6)$ \\
SMP & $3(2,6)$ \\
SMA & $3(2,6)$ \\
Perguruan Tinggi & $1(0,9)$ \\
Pekerjaan & \\
Ibu Rumah Tangga & $30(25,7)$ \\
Pensiunan PNS & $4(3,4)$ \\
Wiraswasta & $2(1,7)$ \\
Petani & $81(69,2)$ \\
& \\
Tingkat Ekonomi & \\
Baik & $9(7,7)$ \\
Rata-rata & $74(63,2)$ \\
Kurang & $34(29,1)$ \\
\hline
\end{tabular}

SD, sekolah dasar; SMP, sekolah menengah pertama; SMA, sekolah menengah atas; PNS, pegawai negeri sipil

Tabel 2. Hubungan Antara Depresi, Faktor Sosiodemografi, Kualitas Hidup, dan Gangguan Kognitif

\begin{tabular}{|c|c|c|c|}
\hline Variabel & $\begin{array}{c}\text { Tanpa Depresi } \\
(\mathrm{n}=93)\end{array}$ & $\begin{array}{l}\text { Depresi } \\
(\mathrm{n}=24)\end{array}$ & $\mathrm{p}$ \\
\hline $\begin{array}{l}\text { Umur (Tahun) } \\
\text { Jenis Kelamin (\%) }\end{array}$ & $68,85 \pm 8,94$ & $70,08 \pm 6,67$ & $0,53^{*}$ \\
\hline - Laki-laki & $47(50,5)$ & $7(29,2)$ & $0,06^{* *}$ \\
\hline $\begin{array}{l}\text { - Perempuan } \\
\text { Status Pernikahan (\%) }\end{array}$ & $46(49,5)$ & $17(70,8)$ & \\
\hline - Menikah & $23(24,7)$ & $6(25)$ & $0,97^{* *}$ \\
\hline $\begin{array}{l}\text { • Tidak menikah/cerai } \\
\text { Tingkat Ekonomi (\%) }\end{array}$ & $70(75,3)$ & $18(75)$ & \\
\hline - Baik & $9(9,7)$ & $0(0)$ & $0,04^{* * *}$ \\
\hline - Rata-rata & $63(67,7)$ & $11(45,8)$ & \\
\hline $\begin{array}{l}\bullet \quad \text { Kurang } \\
\text { Tingkat Pendidikan (\%) }\end{array}$ & $27(22,6)$ & $13(54,2)$ & \\
\hline - $<\mathrm{SMP}$ & $87(93,5)$ & $23(95,8)$ & $0,56^{* * * * *}$ \\
\hline $\begin{array}{l}\bullet \geq \text { SMP } \\
\text { Kualitas Hidup (\%) }\end{array}$ & $6(6,5)$ & $1(4,2)$ & \\
\hline - Baik & $30(32,3)$ & $5(20,8)$ & $0,49^{* * *}$ \\
\hline - Sedang & $50(53,8)$ & $16(66,7)$ & \\
\hline $\begin{array}{l}\text { - Buruk } \\
\text { Gangguan kognitif (\%) }\end{array}$ & $13(14)$ & $3(12,5)$ & \\
\hline - $\mathrm{Ya}$ & $42(45,2)$ & $22(91,7)$ & $<$ \\
\hline - Tidak & $51(54,8)$ & $2(8,3)$ & $0,001^{* *}$ \\
\hline
\end{tabular}

\section{DISKUSI}

Berdasarkan hasil studi ini didapatkan prevalensi depresi dan gangguan fungsi kognitif pada penduduk Desa Pedawa berturut-turut sebesar 20,5\% dan 54,7\%. Prevalensi depresi lebih banyak dialami oleh wanita (70,8\%) dan prevalensi gangguan fungsi kognitif lebih banyak didapatkan pada penduduk dengan depresi $(91,7 \%)$. Hasil pada studi ini serupa dengan studi di Cina yang mendapatkan prevalensi depresi pada populasi usia lanjut sebesar 24,3\% dan lebih sering dialami oleh wanita. ${ }^{2}$ Pada studi lain di Meksiko, prevalensi depresi pada usia lanjut di komunitas dan usia lanjut yang menjalani rawat inap adalah sebesar $13,2 \%$ dan $40 \%{ }^{3}$ Secara umum prevalensi depresi pada usia lanjut di berbagai negara sangat bervariasi, tergantung dari tingkat perkembangan ekonomi, budaya dan gaya hidup. Pada studi ini prevalensi penduduk dengan gangguan kognitif tampak lebih tinggi jika dibandingkan dengan studi-studi lain dimana pada studi di Cina, Spanyol, Amerika dan Kanada prevalensi gangguan fungsi kognitif didapatkan sebesar 12,6\%, 22,2\% dan 16,8\%. 2,4,6 Selain itu pada studi yang dilakukan terhadap usia lanjut pada komunitas di Turki, prevalensi gangguan fungsi kognitif didapatkan hasil yang lebih tinggi yaitu 26,1\%. ${ }^{5}$ Terdapatnya variasi prevalensi gangguan fungsi kognitif ini kemungkinan diakibatkan oleh perbedaan dalam karakteristik sampel yang digunakan (rentang usia, kriteria dan alat diagnosis, tingkat pendidikan serta gaya hidup).

Hubungan antara depresi dan gangguan fungsi kognitif dalam studi ini menunjukkan hasil yang bermakna $(\mathrm{p}<0,05)$. Hasil ini konsisten dengan studi di Cina yang menunjukkan hubungan yang signifikan antara depresi dan gangguan fungsi kognitif $(\mathrm{OR}=3,33$; 95\% KI: 1,97-5,63; $\mathrm{p}<0,001){ }^{2}$ Pada studi kohort di Meksiko juga menunjukkan subjek dengan gejala klinis depresi akan mengalami penurunan skor MMSE dalam kurun waktu 7 tahun jika dibandingkan dengan subjek tanpa keluhan depresi ( $p<0,001$ ). ${ }^{11}$ Gangguan fungsi kognitif dan depresi memiliki keterkaitan satu dengan lainnya. Gangguan fungsi kognitif dikatakan sebagai salah satu faktor risiko independen terjadinya depresi dan sebaliknya beberapa studi juga menunjukkan depresi dapat meningkatkan risiko gangguan fungsi kognitif. Kemampuan proses pikir dan gangguan konsentrasi merupakan salah satu kriteria diagnosis depresi. Pada beberapa studi lain menunjukkan bahwa individu dengan depresi cenderung memiliki penurunan performa terkait aspek neuropsikologis dan gangguan fungsi eksekusi bila dibandingkan dengan individu tanpa depresi. ${ }^{8,9}$ Defisit dalam fungsi eksekutif, penghambatan respon, perencanaan, dan pemantauan kinerja, terkait dengan respon pengobatan jangka panjang yang buruk dan disabilitas fungsional yang lebih besar pada pasien dengan depresi., ${ }^{1,7}$ Gangguan fungsi kognitif paling sering dialami oleh individu usia lanjut dengan 
late-onset depression.

Hasil analisis lain juga menunjukkan terdapat hubungan yang bermakna antara depresi dan tingkat ekonomi, dimana penduduk dengan tingkat ekonomi rendah lebih banyak didapatkan pada penduduk dengan depresi dibandingkan penduduk tanpa depresi $(p<0,05)$. Status sosial ekonomi pada studi di India menunjukkan hubungan yang bermakna terkait depresi. Pada subjek dengan ketergantungan finansial dikatakan lebih banyak mengalami depresi dibandingkan dengan subjek tanpa ketergantungan finansial ( $\mathrm{p}<0,01){ }^{12}$ Studi lain di Eropa juga menunjukkan bahwa status sosio-ekonomi yang rendah terkait dengan depresi dan setiap peningkatan indeks sosio-ekonomi terkait dengan penurunan bermakna odds ratio kejadian depresi (OR = 0,99; KI $95 \% 0,98-0,99$; $<$ < 0,01). ${ }^{13}$ Rendahnya status sosioekonomi memiliki kaitan terhadap rendahnya kesejahteraan, berkurangnya akses pada fasilitas kesehatan, dan aktivitas sosial penduduk di suatu daerah dan makin meningkatkan risiko terjadinya depresi. Depresi telah diketahui berkorelasi secara negatif terhadap kualitas hidup usia lanjut dan hal tersebut konsisten sepanjang waktu tanpa memandang jenis instrumen penapisan kualitas hidup yang dipakai pada berbagai studi. ${ }^{14}$ Pada studi ini hubungan antara depresi dan kualitas hidup tidak menunjukkan hasil yang bermakna ( $\mathrm{p}=$ $0,49)$. Kemungkinan hasil yang tidak bermakna pada studi ini disebabkan oleh sebaran data dan jumlah sampel yang kurang.

Beberapa kelemahan dari studi ini meliputi desain potong lintang dan keterbatasan jumlah sampel. Hendaknya diperlukan suatu penelitian lanjutan dengan desain longitudinal dan skala populasi yang lebih besar agar dapat menilai hubungan kasual antara kejadian depresi dengan penurunan fungsi kognitif dan kualitas hidup di masyarakat.

\section{SIMPULAN}

Pada hasil studi ini menunjukkan bahwa terdapat hubungan bermakna antara depresi dengan penurunan fungsi kognitif dan status ekonomi. Sedangkan hubungan antara depresi dan kualitas hidup tidak didapatkan hasil yang bermakna.

\section{DAFTAR PUSTAKA}

1. Potter GG, Steffens DC. Contribution of depression to cognitive impairment and dementia in older adults. Neurologist. 2007; 13(3): 105117

2. Giri M, Chen T, Yu W, et al. Prevalence and correlates of cognitive impairment and depression among elderly people in the world's fastest growing city, Chongqing, People's Republic of China. Clin Interv Aging. 2016: 12: 1091-1098

3. Leon FG, Ashton AK, D'Mello DA, et al. Depression and comorbid medical illness: therapeutic and diagnostic challenges. J Fam Pract. 2003; suppl:S19-S23

4. Plassman BL, Langa KM, Fisher GG, et al. Prevalence of cognitive impairment without dementia in the United States. Ann Intern Med. 2008;148(6):427-434.

5. Arguvanli S, Akin S, Deniz Safak E, et al. Prevalence of cognitive impairment and related risk factors in community-dwelling elderly in Kayseri, Turkey. Turk J Med Sci. 2015;45(5):1167-1172

6. Lara E, Koyanagi A, Olaya B, et al. Mild cognitive impairment in a Spanish representative sample: prevalence and associated factors. Int $J$ Geriatr Psychiatry. 2016; 31(8): 858-867

7. Gotlib IH \& Joormann J: Cognition and Depression: Current Status and Future Directions. Annu Rev Clin Psychol. 2010; 6:285-312

8. Kessing, LV. Course and cognitive outcome in major affective disorders. Dan Med J. 2015; 62(11): B5160

9. Boone K, Lesser B, Miller B, et al. Cognitive functioning in a geriatric depressed population: relationship of presence and severity of depression to neuropsychological scores. Neuropsychology. 1995;9:390 -398

10. Saracli O, Akca AS, Atasoy N, et al. The Relationship between Quality of Life and Cognitive Functions, Anxiety and Depression among Hospitalized Elderly Patients. Clin Psychopharmacol Neurosci. 2015; 13(2): 194-200

11. Raji MA, Reyes-Ortiz CA, Kuo YF, et al. Depressive symptoms and cognitive change in older Mexican Americans. J Geriatr Psychiatry Neurol. 2007; 20(3): 145-152

12. Saikia AM, Mahanta N, Deka H, et al. Depression in elderly: a community-based study from Assam. IJBAMR. 2016; 5(4): 42-48

13. Freeman A, Tyrovolas S, Koyanagi A, et al. The role of socio-economic status in depression: results from the COURAGE (aging survey in Europe). BMC Public Health; 16(1): 1098-1106

14. Sivertsen H, Bjorklof GH, Engedal K, et al. Depression and Quality of Life in Older Person: A Review. Dement Geriatr Cogn Disord. 2015; 40: 311-339

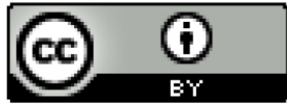

This work is licensed under a Creative Commons Attribution 4.0 International License. 